\title{
O PROCESSO DE OUTSOURCING OFFSHORE DA FUNÇÃO PRODUÇÃO: UM ESTUDO NA TRIKKE TECH INC
}

\section{THE PROCESS OF OFFSHORE OUTSOURCING OF PRODUCTION FUNCTION: A STUDY AT TRIKKE TECH INC}

\author{
Israel Ferreira Júnior*isjunior99@yahoo.com.br \\ * Universidade Federal do Paraná
}

\begin{abstract}
Resumo: Nos últimos anos, tem aumentado a cada dia o número de empresas que utilizam a estratégia do outsourcing, motivadas principalmente pelos ganhos em economia de custo. O objetivo deste artigo é verificar como empresa inovadora utilizou a estratégia do outsourcing offshore de sua produção com vistas ao aumento da competitividade. Com base em revisão de literatura, identificou-se conceitos, características, motivações e benefícios, riscos e problemas, e os principais países ou destinos da prática do outsourcing offshore. Após o levantamento bibliográfico, pesquisa de campo foi realizada na empresa TRIKKE TECH INC. Os dados foram coletados por meio de entrevistas realizadas com um dos proprietários e fundadores da empresa, bem como pela análise de material institucional e publicação sobre a empresa. Após análise dos dados, foi possível verificar o desenvolvimento do processo de utilização da estratégia de outsourcing offshore, os benefícios obtidos e as dificuldades enfrentadas, bem como as soluções adotadas. A utilização da estratégia de outsourcing offshore tem possibilitado à empresa competir em nível mundial com seu produto, em decorrência dos baixos custos de produção. Apesar dos benefícios obtidos com a parceria realizada, a empresa monitora constantemente o relacionamento para evitar problemas e riscos inesperados, inerentes ao processo de outsourcing offshore.
\end{abstract}

Palavras-chave: Outsourcing Offshore, Produção, Competitividade, Parcerias, Negócios Internacionais.

\begin{abstract}
In recent years the number of companies using the outsourcing strategy has increased, driven mainly by gains in cost savings. This article aims to analyze how an innovative company utilized the strategy of offshore outsourcing of their production in order to increase competitiveness. Based on literature review concepts, characteristics, motivations and benefits, risks and problems were identified. After literature review, field research was performed at TRIKKE TECH INC. Data were collected through interviews with one of the owners and founder of the company, as well as through analysis of institutional material and reports about the company. The use of offshore outsourcing strategy has enabled the company to compete worldwide with their product, due to lower production costs. Despite the benefits achieved with the partnership, the company constantly monitors the relationship with the partner to avoid unexpected problems and risks inherent in the process of offshore outsourcing.
\end{abstract}

Keywords: Offshore Outsourcing, Production, Competitiveness, Partnerships, International Business. 


\section{INTRODUÇÃO}

Apesar do destaque obtido entre as empresas na década de 1990, pode-se dizer que o outsourcing não é uma atividade nova. De modo geral, o outsourcing consiste na transferência, de uma organização para outra, da responsabilidade pela execução de atividades (terceirização). Nos últimos trinta anos, a produção têxtil, automotiva e de aço têm sido terceirizada e transferida para outras organizações, muitas vezes de diferentes países, por meio dessa prática (ERBER; SAYED-AHMED, 2005). As atividades que têm sido incluídas no outsourcing vão desde as mais tradicionais até aquelas consideradas como estratégicas para as organizações.

De acordo com Hussey e Jenster (2003), devido ao crescimento de sua utilização, o outsourcing tem alcançado níveis de complexidade cada vez maiores, fazendo com que compradores e fornecedores lidem com questões específicas a cada forma de arranjo utilizado para esse tipo de operação. Tal complexidade está presente, principalmente, no outsourcing offshore feito pelas empresas. A modalidade offshore consiste na transferência de atividades para organizações que se encontram em países diferentes da empresa que realiza o outsourcing.

A transferência do trabalho para outros países primeiro se tornou corrente em indústrias manufatureiras, embora, recentemente, a terceirização de funções de tecnologia da informação (TI) esteja se tornado cada vez mais popular como fonte de vantagem competitiva, com as empresas cortando custos e aumentando a eficiência. Além desses benefícios, Pinna, Laurindo e Pessôa (2003) afirmam que a utilização da prática do outsourcing se deve ao fato de as empresas estarem buscando concentrar seus esforços em atividades consideradas o foco de negócio e terceirizando as que não correspondem à sua competência essencial.

Embora os benefícios sejam grandes, existem riscos envolvidos nesse processo de outsourcing. Dessa forma, as empresas precisam pesar os riscos, custos e recompensas antes de tomar a decisão terceirizar ou transferir suas atividades. Quanto mais vital e estratégica a tarefa, mais cuidado deve ser tomado com essa decisão (KAKUMANU; PORTANOVA, 2006). 
A partir do surgimento do outsourcing, grandes empresas têm feito uso dessa estratégia. Contudo, é importante destacar que micro e pequenas empresas de diferentes mercados têm terceirizado suas atividades na busca da manutenção da competitividade.

Dentro desse contexto, o objetivo deste artigo é verificar como uma empresa inovadora utilizou a estratégia do outsourcing offshore de sua produção com vistas ao aumento da competitividade. Assim, foi realizada uma pesquisa de campo na TRIKKE TECH INC, empresa que comercializa produto inovador e que faz uso do outsourcing offshore.

Após esta introdução, apresenta-se a revisão de literatura sobre o tema. $\mathrm{Na}$ seqüência, são detalhados os procedimentos metodológicos utilizados na pesquisa de campo. Os resultados da pesquisa, incluindo a descrição da empresa e análise dos dados, se encontram no tópico subseqüente. Na parte final do artigo são apresentadas as considerações finais, bem como as limitações do estudo e sugestões para pesquisas futuras.

\section{FUNDAMENTAÇÃO TEÓRICA}

Diversos trabalhos já foram feitos abordando diferentes aspectos do fenômeno do outsourcing. Nesta seção serão apresentados alguns dos principais pontos relacionados a esse tema.

\subsection{Definição conceitual}

Embora seja um fenômeno que pode envolver todas as funções de uma empresa, muitas vezes o outsourcing tem sido definido principalmente com relação à área de TI (JENNEX; ADELAKUN, 2003; ADELAKUN, 2006; FJERMESTAD; SAITTA, 2005; KHAN; FITZGERALD, 2004). Mas, de forma mais ampla, o outsourcing pode ser definido como a transferência de atividades ou processos de diferentes funções para outras organizações. Assim, no outsourcing verifica-se uma relação de cliente e 
fornecedor. Contudo, na medida em que esta prática ganha em complexidade, esse relacionamento evolui para uma parceria, e não apenas uma relação de compra e venda.

$\mathrm{Na}$ literatura verifica-se também grande quantidade de estudos envolvendo o outsourcing offshore. De acordo com Erber e Sayed-Ahmed (2005, p.100), considerando-se o país de origem, esta forma específica de outsourcing pode ser definida como a "realocação dos processos de negócios (incluindo produção, distribuição e serviços de negócios, bem como atividades centrais como pesquisa e desenvolvimento) para locações de baixo custo fora das fronteiras nacionais". Entretanto, é importante destacar que existem outras variáveis ligadas ao outsourcing além da busca pelo menor custo, como, por exemplo, a busca por mão-de-obra qualificada. Os autores ressaltam que o termo serve tanto para bens e produtos como para serviços.

Além disso, Khan e Fitzgerald (2004) destacam que, para se configurar o outsourcing offshore, o fornecedor externo não pode ser uma subsidiária global da empresa cliente.

\subsection{Características}

Conforme o que está sendo objeto de transferência, o outsourcing sempre envolve um considerável grau de troca de informação, coordenação e confiança entre os dois parceiros (ERBER; SAYED-AHMED, 2005). Em decorrência disso, as organizações devem analisar profundamente, antes de qualquer acordo, as atividades que serão objeto de terceirização, bem como as conseqüências de tal opção estratégica.

Erber e Sayed-Ahmed (2005) afirmam que as atividades mais adequadas para o outsourcing offshore são as que consomem tempo e estão claramente definidas como, por exemplo, call centers e suporte e sistemas de administração. Já atividades de negócios que são intimamente entrelaçadas com particularidades nacionais não são transferidas facilmente, quando isso é possível. 
Funções com baixo valor estratégico ou que podem ser tratadas como commodities podem ser facilmente transferidas. Kakumanu e Portanova (2006) entendem que o risco é mínimo pelo fato de elas não constituírem fonte de receita ou vantagem. Funções de nível operacional se encaixam nesse quadro. Quanto mais generalizada a função, mais confiavelmente ela pode ser objeto de outsourcing, e de um modo mais fácil e barato. Os autores complementam que quanto maior o conhecimento exigido da indústria ou da empresa no desempenho de certa função, menor é a probabilidade de ela ser transferida.

Uma organização pode fazer uso de diferentes arranjos em função do tipo de outsourcing empregado. Hussey e Jenster (2003) apresentam quatro tipos de outsourcing: tradicional (transação de compra e venda); atividades periféricas (exigência de poucas capacidades específicas da indústria); atividades e processos críticos (essenciais para o sucesso da organização cliente); e atividades estratégicas e de solução de problemas (ligadas ao centro estratégico da empresa). Os dois últimos tipos possuem os maiores retornos, mas também envolvem os maiores riscos para as empresas.

De acordo com Erber e Sayed-Ahmed (2005), um projeto offshore pode ser dividido em 3 fases: Seleção do fornecedor; Período de Transição; Gerenciamento do contrato. A fase 1 pode durar aproximadamente 6 meses e a escolha adequada e cuidadosa do fornecedor é algo imprescindível para o sucesso do outsourcing. Na fase 2 ocorre a transferência do conhecimento dos trabalhadores da empresa para os do fornecedor. É um período que envolve muitas viagens, treinamento e adaptação cultural. Em um estado de transição, os custos dobram: são pagos os trabalhadores da empresa e os do fornecedor. A fase 3 consiste no acompanhamento do relacionamento e verificação do cumprimento do contrato. Além disso, nessa fase também acontece a alteração ou o aperfeiçoamento do contrato, caso seja necessário.

Para o estabelecimento de uma base estratégica consistente para o outsourcing, Insinga e Werle (2000) apresentam uma metodologia que possibilita uma revisão sistemática em termos de: alinhamento do outsourcing com a estratégia de negócios da empresa; clarificação das capacidades e competências centrais; identificação de gaps 
estratégicos e estratégias específicas para economias de custo; reconhecimento das dependências e vulnerabilidades da empresa. De acordo com esses autores, as atividades da empresa são avaliadas em relação ao seu potencial para o alcance da vantagem competitiva e à capacidade interna da empresa para o desempenho delas. Dessa forma elas são classificadas como: atividades-chave, atividades emergentes, atividades básicas e atividades de commodities.

O aumento do interesse no outsourcing offshore é decorrente também do constante desenvolvimento de tecnologias digitais que acabam facilitando a comunicação organizacional, bem como a coordenação e o gerenciamento dos relacionamentos entre empresas (KHAN; FITZGERALD, 2004).

Em seu estudo, Khan e Fitzgerald (2004) se propuseram a analisar os principais fatores que afetariam o processo de tomada de decisão no outsourcing offshore. Os fatores de maior significância identificados foram:

1) fatores organizacionais (fator inicial);

2) fatores tecnológicos (fator de diferenciação);

3) fatores geográficos ou ambientais (fator de oportunidade); e

4) fatores processuais (fator de sucesso).

\subsection{Motivações ou Benefícios}

Ao fazerem uso do outsourcing as empresas têm como um de seus objetivos o aumento da competitividade frente às outras empresas, por meio do uso eficiente de seus recursos. Assim, a meta é fazer mais com menor uso possível dos recursos internos, procurando-se alcançar maiores retornos. Com o outsourcing, além da competitividade, as empresas conseguem obter maior flexibilidade para reagir às mudanças ambientais (INSINGA; WERLE, 2000; KAKUMANU; PORTANOVA, 2006).

Para fazer mais com menos, Insinga e Werle (2000) afirmam que uma empresa deve focar seus recursos limitados naquelas atividades que são essenciais para a sobrevivência e devem alavancar as atividades que são periféricas. De acordo com Erber e Sayed-Ahmed (2005), quando cada empresa foca em suas próprias 
competências centrais, é possível alcançar maiores ganhos em eficiência e lucratividade.

O outsourcing reduz a quantidade dos custos gastos em investimentos fixos que, com a volatilidade da demanda, poderia levar subutilização dos fatores produtivos. Por meio do outsourcing de alguma capacidade de produção a subcontratados, uma empresa pode ganhar flexibilidade suficiente para ser capaz de utilizar sua própria capacidade em um nível consistentemente alto (ERBER; SAYED-AHMED, 2005).

$\mathrm{Na}$ literatura sobre o tema, o principal fator identificado que leva às empresas a buscarem o outsourcing é a redução de custo (HUSSEY; JENSTER, 2003; ERBER; SAYED-AHMED, 2005; KAKUMANU; PORTANOVA, 2006; KHAN; FITZGERALD, 2004). Empresas que fazem uso do outsourcing podem cortar custos de trabalho, tempo de desenvolvimento de $\mathrm{Tl}$, custos de manutenção e estrutura de tempo de processos de produção em geral. Assim, alternativa do outsourcing offshore tem se mostrado cada vez mais atraente para as empresas.

A terceirização de funções e atividades para países com custos de trabalho e remuneração de baixo custo pode ajudar na redução de custos fixos. Em muitas localidades a mão-de-obra é qualificada, mas com um custo bem menor, sem comprometer a qualidade (KHAN; FITZGERALD, 2004; ERBER; SAYED-AHMED, 2005; KAKUMANU; PORTANOVA, 2006). Além disso, é importante destacar que este tipo de outsourcing pode ser motivado pela escassez de mão-de-obra qualificada.

O fato de focar em suas funções centrais do negócio possibilita às empresas oferecer melhores produtos e serviços para seus clientes. Empresas que usam o outsourcing também obtêm benefícios de economia de escala e acesso à especialistas de acordo com suas necessidades (KAKUMANU; PORTANOVA, 2006).

Kakumanu e Portanova (2006) destacam que, atualmente, o uso de diferentes centros de offshore possibilita às empresas a utilização da estratégia de trabalho de 24 horas todos os dias da semana. Isto acontece porque as empresas podem escolher realizar o offshore em diferentes países levando em consideração os diferentes fusos horários. 


\subsection{Riscos ou Problemas}

Apesar das empresas terem a possibilidade de contar com os benefícios apresentados, a estratégia de outsourcing não é isenta de riscos. Portanto, faz necessário que as empresas considerem e avaliem todos os riscos e custos inerentes a tal opção estratégica (KAKUMANU; PORTANOVA, 2006).

As empresas que se utilizam do outsourcing offshore estão sujeitas a riscos de diferentes tipos. Um destes riscos se refere à questão da segurança. Bens e informações em propriedade de outras empresas no exterior são muito mais difíceis de proteger. Ademais, os custos para garantir a segurança e reduzir esse tipo de risco podem ser muito altos, comprometendo as economias obtidas (KAKUMANU; PORTANOVA, 2006).

No processo de terceirização de algum processo ou função, existe sempre a transferência de uma quantidade significativa de controle gerencial para a empresa fornecedora. O que acaba criando o risco da diminuição do controle sobre a cadeia de fornecimento (ERBER; SAYEDAHMED, 2005).

Outro risco que as empresas podem correr está relacionado à qualidade do pessoal e do trabalho, o que muitas vezes pode não ser garantida. Problemas de atraso ou baixa qualidade se agravam de acordo com o grau de dependência em relação aos fornecedores (KAKUMANU; PORTANOVA, 2006).

No outsourcing offshore existem riscos tais como: problemas de infra-estrutura, barreiras culturais, barreiras de linguagem (verbal e de dados) e diferenças de leis e regulamentos entre os países (KHAN; FITZGERALD, 2004).

Kakumanu e Portanova (2006) alertam que problemas de língua e de cultura podem comprometer a estratégia offshore, gerando atritos entre as empresas levando a ineficiência e impedindo o estabelecimento da confiança necessária. Dessa forma, os autores afirmam que é preciso respeito mútuo com relação à cultura corporativa e nacional de cada empresa.

Mudanças econômicas, políticas e regulatórias no ambiente em que offshore se realiza podem gerar custos inesperados para as empresas. Uma saída para as 
empresas é diversificar os fornecedores e países para a realização do outsourcing (ERBER; SAYED-AHMED, 2005). Mas é importante destacar que existem custos associados à mudança de fornecedores, especialmente no outsourcing offshore.

Em muitos casos, as decisões de outsourcing têm motivações de curto prazo. Então, um risco enfrentado pelas empresas se refere às inconsistências e divergências em relação aos custos e benefícios de curto e longo prazo, devendo isso ser levado em consideração (ERBER; SAYED-AHMED, 2005; KAKUMANU; PORTANOVA, 2006).

\subsection{Principais Países ou Destinos}

Cada vez mais os países estão procurando se estabelecer como centros provedores de trabalho de baixo custo como forma de aumentar o nível de emprego e impulsionar suas economias (KAKUMANU; PORTANOVA, 2006). A China tem despontado como principal destino para o offshore da produção, enquanto a Índia se constitui na localidade onde mais se recebe a transferência de serviços de empresas de outros países, principalmente aqueles ligados à função de TI. A Índia possui essa posição de destaque em decorrência de fatores, como: baixo custo do trabalho, alta qualidade do trabalho e experiência em uma variedade de serviços (ERBER; SAYEDAHMED, 2005).

Jennex e Adelakun (2003), a partir de intensa revisão da literatura, identificaram os fatores críticos de sucesso para o outsourcing offshore, os quais podem ser agrupados da seguinte forma: pessoal e recursos humanos; infra-estrutura técnica; interface com clientes; infra-estrutura de negócios; e interface regulatória.

Com base nesses fatores, Adelakun (2006) discute a questão da atratividade e a disponibilidade de um país para receber o outsourcing offshore. Segundo este autor, uma localidade é considerada atrativa e pronta quando a maioria dos fatores críticos é identificada em seu contexto interno.

Khan e Fitzgerald (2004) destacam que fornecedores de outsource offshore têm investido pesadamente em educação técnica, buscando prover um pronto suprimento de programadores altamente qualificados em custo relativamente baixo comparado com 
EUA e Europa. Algumas localidades, como Índia, Singapura e Filipinas, têm melhorado sua infra-estrutura (telecomunicações), além de oferecer incentivos fiscais para tornar o outsourcing offshore mais atrativo.

\section{PROCEDIMENTOS METODOLÓGICOS}

A pesquisa realizada neste estudo pode ser classificada como qualitativa, pois esta abordagem busca entender os fenômenos, segundo a visão dos indivíduos envolvidos com a situação objeto de estudo (NEVES, 1996). Uma das características de uma pesquisa qualitativa é o seu caráter descritivo (GODOY, 1995). Assim, por buscar expor as características de um determinado fenômeno (VERGARA, 1998), esta pesquisa também se classifica como descritiva.

O estudo realizado foi dirigido para responder a seguinte pergunta de pesquisa: Como ocorre o outsourcing offshore da função produção na empresa TRIKKE? Para tanto, foi realizado uma pesquisa de campo na empresa TRIKKE TECH Inc. A pesquisa de campo é um método qualitativo que possibilita ao pesquisador, após a fase de levantamento bibliográfico, ampliar o seu conhecimento sobre o assunto por meio do contato com o fenômeno em seu contexto real (MARCONI; LAKATOS, 1996).

Antes de iniciar a pesquisa de campo, realizou-se um levantamento bibliográfico em periódicos e anais de eventos sobre o tema de outsourcing. Tal procedimento possibilitou a identificação de alguns dos principais aspectos ligados ao assunto em questão. Para fins de triangulação, utilizou-se material institucional da empresa, bem como artigo publicado tendo como objeto de estudo a TRIKKE (SEIFERT JUNIOR; FERNANDES, 2005).

Os dados primários foram coletados por meio de duas entrevistas com um dos sócios e fundador da empresa. A primeira entrevista foi com uso de roteiro semiestruturado e teve a duração de aproximadamente 60 minutos. Já a segunda entrevista foi feita por meio eletrônico e com uso de questionário, respondido pelo entrevistado, visando complementar as informações levantadas anteriormente e esclarecer algumas dúvidas. Esta última entrevista teve também como um de seus objetivos a validação 
dos dados e, conseqüentemente, dos resultados da pesquisa. As entrevistas foram gravadas e transcritas para realização de análise adequada. Após a coleta dos dados, estes foram analisados dentro de uma abordagem qualitativa e interpretativa, tendo como base o referencial teórico levantado.

\section{RESULTADOS}

\subsection{A Empresa TRIKKE}

A trajetória da empresa TRIKKE pode ser dividida em dois momentos principais: uma primeira fase de criação no Brasil e uma segunda fase marcada pela expansão e atuação internacional. A empresa surgiu como uma idéia de dois paranaenses que desenvolveram, no final da década de 80 , um protótipo de um novo tipo de veículo, similar a um patinete, movido por meio da execução de movimentos angulares pelo usuário. A tecnologia de tripla cambagem (3CV) foi patenteada e o produto batizado como Trikke (Figura 1).

O Trikke é um produto que serve para a prática de atividades físicas, trazendo benefícios para a saúde de todo o corpo.

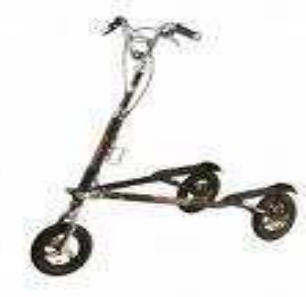

Figura 1 - Trikke

Fonte: site da empresa

Com a possibilidade de comercializar o produto, os inventores buscaram estruturar uma empresa para esse fim. A primeira série de Trikke, produzida em Curitiba, foi vendida para o governo do Estado do Paraná. Inicialmente, a idéia era comercializar o produto no país. Entretanto, devido ao ambiente econômico desfavorável no governo Collor, a empresa não conseguiu sobreviver, fazendo com que seus criadores buscassem outras atividades. 
Após um período de quase 10 anos, um dos inventores do Trikke decidiu retomar o projeto, em virtude de seu grande potencial. Contudo a estratégia adotada foi a de tentar comercializar o Trikke no mercado norte-americano, mas mantendo a produção no Brasil. No processo de conquistar mercado nos Estados Unidos, a empresa ganhou um novo sócio americano. Dessa forma, foi organizada com sede no EUA a empresa TRIKKE TECH INC., ficando o controle da empresa dividido entre três sócios brasileiros e um americano.

A estrutura organizacional da empresa se enquadra, nas palavras do entrevistado, "dentro do novo conceito de trabalho mundial", propiciado pelas novas da tecnologia da informação e comunicação. Na sede da empresa nos EUA se concentra a área de administração, marketing e comercial, onde trabalham dez pessoas. A área de pesquisa, desenvolvimento e engenharia se encontra no Brasil sob responsabilidade de três membros da empresa. E a produção do Trikke é toda feita na China. Naquele país a empresa possui um engenheiro responsável pelo acompanhamento da produção. No total, a TRIKKE é composta por 14 pessoas. Segundo números do ano de 2006, a produção anual da empresa é de cerca de 50 mil unidades, com faturamento anual de 6 milhões de dólares. As vendas da empresa estão distribuídas da seguinte forma: $81 \%$ nos Estados Unidos e Canadá; 15\% na Europa; 3\% na Ásia; e 1\% na América do Sul.

\subsection{Outsourcing Offshore da Produção}

Embora o objetivo da empresa fosse o de produzir o Trikke no Brasil, esta estratégia acabou se mostrando inadequada, principalmente por causa do custo de produção. No Brasil, o Trikke era produzido em uma metalúrgica terceirizada de porte médio. Ao analisar o potencial do mercado norte-americano, e outras possibilidades em nível mundial, os proprietários perceberam que não teriam condições competir fabricando o produto no Brasil.

$\mathrm{Na}$ busca por maior divulgação do produto, a empresa passou a participar de feiras e eventos. E foi numa dessas feiras que os sócios conheceram um dos maiores 
fabricantes de patinetes da China. E foi a partir desse contato que surgiu a possibilidade da terceirização da produção para a China.

Para a formalização da parceria, um dos sócios viajou à China, com o objetivo de conhecer a fábrica e discutir os aspectos contratuais e técnicos do acordo. Um dos primeiros benefícios desse relacionamento foi a melhoria do produto. Com base na tecnologia utilizada pelos chineses na produção de patinetes, foram sugeridas por eles adaptações no Trikke, as quais foram aceitas e incorporadas. Assim, na opinião do entrevistado, houve um "agregamento de um conhecimento" advindo da experiência dos chineses, sendo esse processo um "avanço no negócio".

De acordo com o entrevistado, a TRIKKE teve também como benefício a diminuição nos custos ligados à produção. Todo o investimento no ferramental necessário para a produção dos Trikkes ficou por conta dos chineses, além da utilização de toda capacidade instalada já existente.

Entretanto, a empresa teve problemas com esse primeiro fornecedor, que começou a não respeitar adequadamente os contratos firmados. $O$ fabricante do Trikke na China fazia venda do produto sem o pagamento de royalties e tentou patentear o produto nos EUA. Além disso, um dos engenheiros que participou na implantação da linha de produção do Trikke montou a primeira fábrica pirata do produto. Cabe destacar também que outras fábricas piratas surgiram na seqüência em solo chinês, dado o sucesso já alcançado pelo Trikke no mundo (SEIFERT JÚNIOR; FERNANDES, 2005).

Diante desses problemas, a empresa buscou outros fabricantes para o Trikke. Atualmente, a empresa conta com duas fábricas, também na China, que receberam a produção terceirizada. A estratégia de contar com outros parceiros decorre da percepção dos dirigentes de que, por não ter fábrica própria, a TRIKKE não poderia ficar refém dos interesses próprios de um único fornecedor. De acordo com o entrevistado, "é preciso ter um equilíbrio". Além disso, existem planos para se voltar a produzir o Trikke no Brasil. Contudo ele ressalta que deve ser encontrada uma alternativa que tenha os mesmos custos de produção verificados na China.

Algumas outras dificuldades foram identificadas com relação ao outsourcing offshore da produção na China. A primeira delas diz respeito às dificuldades de 
linguagem ou comunicação. Segundo o entrevistado, o fato de muitas vezes a comunicação ter que ser realizada com o auxílio de intérpretes dificulta esse processo. Mas, o entrevistado acredita que essa dificuldade será superada em pouco tempo, na medida em que os chineses ampliam seus negócios pelo mundo.

A maior dificuldade mencionada pelo entrevistado está relacionada com a garantia da qualidade do produto Trikke exigida pela empresa. No início dos relacionamentos com as fábricas, o maior desafio dos dirigentes da TRIKKE foi fazer os chineses entenderem e incorporarem na produção o nível de qualidade desejado, cumprindo todas as exigências e especificações técnicas. Isto fez com que muitos produtos fossem recusados, gerando alguns conflitos entre as partes. Entretanto, atualmente as partes já chegaram a um entendimento quanto a essa questão.

Para fins de acompanhamento e gestão do relacionamento entre a TRIKKE e seus fornecedores, a empresa conta com um engenheiro chinês no desempenho dessas atividades. Esse engenheiro é um ex-funcionário de uma das fábricas e foi convidado pela TRIKKE para cuidar dessa área da produção. O processo de controle de qualidade é feito tanto na origem, com esse engenheiro, quanto no destino, nos EUA ou Brasil.

Apesar das distâncias geográficas, o relacionamento entre as diferentes áreas da empresa ocorre de modo bem estreito. Além do uso das tecnologias da informação, este nível de interação é possível, segundo o entrevistado, pelo fato de a TRIKKE ser composta de poucas pessoas. Dessa forma, "todas elas conhecem basicamente todo o processo". Mesmo o pessoal das fábricas na China, que são terceirizados, contribui de forma efetiva com sugestões para melhoria do produto e redução de custos.

$\mathrm{Na}$ opinião do dirigente entrevistado, o relacionamento com as empresas terceirizadas na China é algo que está amadurecendo com o tempo, pois os interesses de ambas as partes sempre estão sendo trabalhados. Segundo ele, "sempre se está buscando um ponto de equilíbrio no negócio". 


\subsection{Análise dos Dados}

De acordo com Erber e Sayed-Ahmed (2005), um projeto de offshore pode ser dividido em três fases: seleção do fornecedor; período de transição; e gerenciamento de contrato. No caso TRIKKE, a fase de seleção de fornecedor ficou caracterizada por ocasião dos contatos realizados com o fabricante de patinetes nas feiras e pelas viagens dos dirigentes à China para conhecerem a fábrica e negociarem o acordo. $O$ período de transição é marcado pela busca da empresa em fazer com que os chineses trabalhassem de acordo com o padrão técnico e de qualidade exigido. Por fim, na fase de gerenciamento de contrato, que ocorre correntemente, pode-se destacar a contratação, por parte da TRIKKE, de um engenheiro para acompanhar todo o processo de outsourcing junto às fábricas.

Corroborando com toda a literatura revisada anteriormente, o maior benefício da TRIKKE e também a principal motivação para o outsourcing offshore, de acordo com o entrevistado, se relacionam à economia no custo de produção, que possibilita à empresa competir no mercado mundial. Além disso, a empresa se beneficiou do fato de utilizar a capacidade já instalada da empresa, bem como dos conhecimentos tecnológicos e expertise dos chineses.

Mas como nenhum relacionamento de outsourcing possui apenas benefícios, a empresa também enfrentou dificuldades como, por exemplo, problemas com a qualidade do produto e de desrespeito ao contrato por parte do fornecedor inicial. Além disso, problemas de comunicação e linguagem foram identificados no relacionamento, os quais também são mencionados na literatura. A estratégia de adotar mais de um fornecedor é uma tentativa da TRIKKE de minimizar o risco de dependência de um único fabricante.

Mesmo com dois fabricantes terceirizados na China, um dos países mais procurados para o outsourcing offshore da produção, a empresa tem planos de produzir o Trikke no Brasil. Contudo essa decisão estratégica vai depender das condições nacionais de atratividade e disponibilidade (ADELAKUN, 2006) para a produção de baixo custo. 
O quadro 1 apresenta uma síntese das evidências encontradas na literatura sobre o outsourcing offshore e os principais resultados da pesquisa realizada na empresa TRIKKE.

\begin{tabular}{|c|c|c|}
\hline & Literatura & TRIKKE \\
\hline $\begin{array}{l}\text { Fases de um projeto } \\
\text { de outsourcing } \\
\text { offshore }\end{array}$ & $\begin{array}{l}\text { Fase 1: Seleção do } \\
\text { fornecedor } \\
\text { Fase 2: Período de } \\
\text { Transição (transferência de } \\
\text { conhecimento, treinamento e } \\
\text { adaptação cultural) } \\
\text { Fase 3: Gerenciamento do } \\
\text { Contrato }\end{array}$ & $\begin{array}{l}\text { Seleção: Contatos em } \\
\text { feiras e visitas às fábricas } \\
\text { Transição: Ajustes no } \\
\text { padrão de produção e na } \\
\text { qualidade do produto } \\
\text { Gerenciamento: } \\
\text { Funcionário da empresa } \\
\text { para acompanhar a } \\
\text { produção }\end{array}$ \\
\hline $\begin{array}{l}\text { Motivações e } \\
\text { benefícios }\end{array}$ & $\begin{array}{l}\text { Aumento da competitividade } \\
\text { Uso eficiente dos recursos } \\
\text { Flexibilidade } \\
\text { Redução de Custos } \\
\text { Economias de escala } \\
\text { Acesso à especialistas e à } \\
\text { mão-de-obra qualificada }\end{array}$ & $\begin{array}{l}\text { Economia do custo de } \\
\text { produção } \\
\text { Aumento de } \\
\text { competitividade } \\
\text { Conhecimento tecnológico } \\
\text { e expertise dos parceiros } \\
\text { Capacidade instalada dos } \\
\text { fornecedores }\end{array}$ \\
\hline Riscos e problemas & $\begin{array}{l}\text { Segurança de bens e } \\
\text { propriedades } \\
\text { Diminuição do controle } \\
\text { sobre a cadeia de } \\
\text { fornecimento } \\
\text { Qualidade do trabalho e do } \\
\text { produto } \\
\text { Atrasos } \\
\text { Barreiras culturais e de } \\
\text { linguagem }\end{array}$ & $\begin{array}{l}\text { Qualidade do produto } \\
\text { Problemas de comunicação } \\
\text { e linguagem } \\
\text { Pirataria do produto }\end{array}$ \\
\hline Principais destinos & $\begin{array}{l}\text { China, Índia, Singapura e } \\
\text { Filipinas }\end{array}$ & China \\
\hline
\end{tabular}

Quadro 1 - Evidências encontradas na literatura e na empresa pesquisada

Fonte: elaborado pelo autor

\section{CONSIDERAÇÕES FINAIS}

Por meio deste estudo, buscou-se verificar como foi utilizada a estratégia de outsourcing offshore em uma empresa brasileira. E, diferentemente de grande parte dos 
últimos estudos sobre o tema, este trabalho apresenta a transferência para o exterior da função produção de uma empresa com um produto inovador.

A utilização da estratégia do outsourcing offshore tem possibilitado à empresa TRIKKE competir em nível mundial com seu produto, em decorrência dos baixos custos de produção. Além disso, mesmo a empresa sendo composta por 14 pessoas, o relacionamento com fornecedores na China possibilita a comercialização de grandes volumes do produto e a obtenção de um faturamento bem superior a empresas deste porte. Tal situação pode ser decorrente do fato de a empresa comercializar um produto inovador, que possibilita a cobrança de preços diferenciados.

Apesar dos benefícios obtidos, a empresa deve estar atenta com o andamento da parceria, pois os relacionamentos de outsourcing apresentam problemas e riscos que podem trazer custos inesperados. O fato de a empresa ter um funcionário específico para acompanhar as parcerias de terceirização demonstra que lições foram aprendidas dos problemas anteriores e se constitui numa tentativa de minimizar riscos futuros.

O início dos relacionamentos com os fabricantes na China foi possibilitado por meio de contatos pessoais. Entretanto é inegável que as condições ambientais favoráveis do país foram determinantes para o estabelecimento e ampliação dos acordos de outsourcing.

Uma das limitações do presente estudo está relacionada com a impossibilidade de entrevistar todos os dirigentes da empresa, uma vez que eles se encontravam distantes geograficamente e com dificuldades de agenda. $O$ fato de a empresa possuir uma estrutura descentralizada impediu a realização de um estudo de campo aprofundado, configurando isso mais uma limitação do estudo.

Pesquisas futuras poderiam focar em dois pontos principais: a identificação dos fatores críticos de atratividade e disponibilidade para o recebimento do outsourcing no Brasil; e estudos sobre outsourcing offshore de outras funções além daquelas ligadas a TI. 


\section{REFERÊNCIAS}

ADELAKUN, O. Offshore it outsourcing - readiness vs. attractiveness: the case of Ssouth Africa. Journal of Global Information Technology Management, 2006.

ERBER, G.; SAYED-AHMED, A. Offshore outsourcing: a global shift in the present it industry. Intereconomics, v. 40, n.2, p.100-112, 2005.

FJERMESTAD, J.; SAITTA, J.A. A Strategic management framework for it outsourcing: a review of the literature and the development of a success factors model. Journal of Information Technology Case and Application Research, v.7, n.3, p. 42-60, 2005.

GODOY, A. A pesquisa qualitativa e sua utilização em administração de empresas. Revista de Administração de Empresas. São Paulo, v. 35, n. 4, p. 65-71, 1995.

HUSSEY, D.; JENSTER, P. Outsourcing: the supplier viewpoint. Strategic Change, v.12, n.1, p. 7-20, 2003.

INSINGA, R.; WERLE, M.J. Linking Outsourcing to Business Strategy. The Academy of Management Executive, v.14, n.4, p. 58-70, 2000.

JENNEX, M.E.; ADELAKUN, O. success factors for offshore information system development. Journal of Information Technology Cases and Applications, v.5, n.3, p.12-31, 2003.

KAKUMANU, P.; PORTANOVA, A. Outsourcing: its benefits, drawnbacks and other related issues. Journal of American Academy of Business, v.9, n.2, p.1-7, 2006.

KHAN, N.; FITZGERALD, G. Dimensions of Offshore Outsourcing Business Models. Journal of Information Technology Cases and Application, v.6, n.3, p. 35-50, 2004.

MARCONI, M..; LAKATOS, E. Técnicas de pesquisa: planejamento e execução de pesquisas, amostragens e técnicas de pesquisas, elaboração, análise e interpretação de dados. 3. ed. São Paulo: Atlas, 1996.

PINNA, C.; LAURINDO, F.; PESSÔA, M. Uma abordagem para definição de processos de gestão e monitoração de outsourcing em TI baseada em indicadores. In: SEMINARIO LATINO-IBEROAMERICANO DE GESTIÓN TECNOLÓGICA ALTEC, 10, 2003, Cidade do México. Anais... Cidade do México: ALTEC, 2003.

SEIFERT JÚNIOR, R.; FERNANDES, B. A Formação de esquemas interpretativos em empreendimentos nascidos globais: 0 caso da trikke. In: WORKSHOP DE INTERNACIONALIZAÇÃO DE EMPRESAS - COPPEAD/UFRJ, 5, 2005. Anais... Rio de Janeiro: COPPEAD, 2005. 
VERGARA, S.C. Projetos e relatórios de pesquisa em administração. São Paulo: Atlas, 1998.

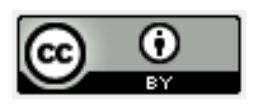

Artigo recebido em 13/07/2009 e aceito para publicação em 03/10/2010. 